\title{
The Expression Level of the 3a Movement Protein Determines Differences in Severity of Symptoms Between Two Strains of Tomato Aspermy Cucumovirus
}

\author{
Ignacio M. Moreno ${ }^{1,2}$, Juan José Bernal ${ }^{1}$, Blanca García de Blas ${ }^{1}$, Emilio Rodriguez-Cerezo ${ }^{2}$, and \\ Fernando García-Arenal ${ }^{1,2}$ \\ ${ }^{1}$ Departamento de Biotecnología, E.T.S.I. Agrónomos, Ciudad Universitaria s/n. 28040 Madrid, Spain; \\ ${ }^{2}$ Centro Nacional de Biotecnología CSIC, Campus de Cantoblanco, 28049 Madrid, Spain \\ Received 5 June 1996. Accepted 7 November 1996.
}

Two strains of tomato aspermy cucumovirus, 1-TAV and V-TAV, differ in the severity of the symptoms induced in Nicotiana tabacum: 1-TAV induces a severe chlorotic mottle that appears 5 days post inoculation (d.p.i.) in the second systemic leaf, while V-TAV-infected plants show a mild chlorotic mottle, unevenly distributed in the leaf lamina, that appears 7 d.p.i. in the third or fourth systemic leaf. The manipulation of full-length cDNA clones giving infectious transcripts of V-TAV RNAs 1, 2, and 3 and 1-TAV RNA 3 revealed that the slow, mild phenotype of V-TAV maps to the movement protein (MP) gene. By site-directed mutagenesis it was further shown that this phenotype co-segregates with a single nucleotide substitution that introduces an in-frame UAA stop codon at the fourth position of the MP open reading frame of V-TAV. The presence of this stop codon results in a diminished expression of the MP in both tobacco protoplasts and leaves. Analyses of the progress of infection and of the time course of MP and coat protein accumulation show that the low level of MP in V-TAV-infected leaves limits the rate of cell-to-cell movement and leads to the mild phenotype. Data from the infectivity of RNA 3 transcripts with or without this stop codon, plus data from in vitro translation of virion or transcript RNA 3, suggest that the small amount of MP observed in V-TAV-infected leaves is expressed from a minor RNA 3 subpopulation lacking the stop codon.

Additional keywords: cucumber mosaic virus, full-length clones, nucleotide sequence.

The molecular analysis of virus determinants for symptom induction in their host plants has progressed significantly during the last 10 years, giving a complex view of this phenomenon. In fact, a role in symptom determination has been reported for most viral-encoded proteins, or their encoding sequences, as well as for noncoding sequences, depending on the particular virus/host interaction (for instance, see Daw-

Corresponding author: F. García-Arenal

E-mail: agrovirus@samba.cnb.uam.es son's 1992 review for the tobamoviruses). Reduced symptom severity has been associated with reduced viral replication, reduced cell-to-cell or long-distance spread efficiency, and a combination of these factors (Watanabe et al. 1987; Holt et al. 1990; Roosinck and Palukaitis 1990).

We present here the analysis of the determinants of tomato aspermy cucumovirus (TAV) affecting the severity of symptoms in tobacco plants. TAV is similar to the type member of the cucumovirus genus, cucumber mosaic virus (CMV), which has been extensively characterized (Palukaitis et al. 1992). As in the case of CMV, TAV has a single-stranded, plus sense RNA tripartite genome in which the genomic segments are named RNAs 1, 2, and 3 in order of decreasing molecular mass. The complete nucleotide sequences of RNAs 1 and 2 of the V strain of TAV (V-TAV) and of RNA 3 of strains C and P have been reported (O'Reilly et al. 1991; Moriones et al. 1991; Bernal et al. 1991; Salánki et al. 1994), showing a genetic organization homologous to CMV: RNA 1, approximately 3,400 nucleotides (nt) long, has a single open reading frame (ORF) encoding the p1a protein; RNA 2 (3,200 nt) and RNA 3 (2,200 to 2,400 nt) each encode two proteins-p2a and p2b for RNA 2, and p3a and the coat protein (CP) for RNA 3. For CMV, it has been shown that p1a and p2a are part of the viral RNA dependent RNA polymerase (Hayes and Buck 1990). The p3a is the movement protein (MP) (Kaplan et al. 1995) that potentiates cell-to-cell spread. The CP, in addition to its structural function, contains determinants for symptoms (Sleat et al. 1994) and vector transmission (Chen and Francki 1990; Perry et al. 1994). It is also needed for cell-to-cell movement (Suzuki et al. 1991; Boccard and Baulcombe 1993) and has host-specific determinants for systemic spread (Taliansky and García-Arenal 1995). A role in host-specific systemic movement has also been shown for p2b (Ding et al. 1995b). Although direct information on the function of TAVencoded proteins is scant, the high sequence conservation of CMV and TAV suggests that these viruses encode proteins with the same functions.

In the course of studies on TAV as a helper for CMV satellite RNAs (Moriones et al. 1992), it was observed that severity of symptoms on tobacco varied depending on the strain. Here we show that these differences in severity of strains 
1-TAV and V-TAV may be due to the slower rate of spread of the milder strain in the host plant, associated with low-level accumulation of its MP. This diminished 3a-MP accumulation results from the presence of an ochre stop codon interrupting the $3 \mathrm{a}$ ORF in the milder strain. Quantitative results on virus spread and p3a accumulation are also reported, which contribute to understanding the concentration ranges at which p3a promotes cell-to-cell movement.

\section{RESULTS}

\section{Genetic mapping of differences in pathogenicity of 1-TAV and V-TAV.}

The V-TAV strain induced milder symptoms more slowly than 1-TAV, when inoculated to tobacco (Nicotiana tabacum L. 'Xanthi nc') For 1-TAV, symptoms appeared at 5 days post inoculation (p.i.) in the first or second systemic leaf. These symptoms were manifest as an initial vein clearing that evolved to severe chlorotic mottle and ringspot at 2 weeks p.i. (Table 1). In tobacco plants infected with V-TAV, symptoms first appeared at 7 days p.i., typically in the third or fourth systemic leaf. In addition to their slow development, these VTAV symptoms were milder than those for 1-TAV (mild chlorotic mottle or ringspot) and were unevenly distributed on the leaf lamina (Table 1).

To map the genetic determinants for these different symptom phenotypes, full-length clones giving infectious transcripts were used. Full-length clones were obtained for RNAs $1\left(\mathrm{pV}_{1}\right)$ and $2\left(\mathrm{pV}_{2}\right)$ of V-TAV and for RNA $3\left(\mathrm{pV}_{3}\right.$ and $\left.\mathrm{p} 1_{3}\right)$ of both V-TAV and 1-TAV. Tobacco plants were inoculated with full-length capped transcripts of V-TAV RNAs 1 and $2\left(\mathrm{~V}_{1}\right.$ and $\mathrm{V}_{2}$, respectively) in combination with RNA 3 transcripts from either V-TAV $\left(\mathrm{V}_{3}\right)$ or 1-TAV $\left(1_{3}\right)$. Only the combination $\mathrm{V}_{1} \mathrm{~V}_{2} 1_{3}$ produced a detectable infection in tobacco plants. Thus, transcript $\mathrm{V}_{3}$ was not infectious for tobacco plants.

The nucleotide sequences of RNA 3 of V-TAV and 1-TAV were determined from these full-length cDNA clones and are shown aligned in Figure 1. They are 98\% similar, with most differences located in noncoding regions: 6 point substitutions in the 89-nt-long $5^{\prime}$ untranslated region (UTR), 14 point substitutions and 6 nt deletions in the 506-nt-long $3^{\prime}$ UTR, and 2

Table 1. Symptom induction and infectivity for different tomato aspermy cucumovirus (TAV) strains or isolates in tobacco plants

\begin{tabular}{lcccc}
\hline & \multicolumn{2}{c}{$\begin{array}{c}\text { Appearance of } \\
\text { symptoms }\end{array}$} & & \\
\cline { 2 - 3 } Inocula & d.p.i. $^{\text {a }}$ & $\begin{array}{c}\text { Systemic } \\
\text { leaf }\end{array}$ & Systemic symptoms & Infectivity \\
\hline 1-TAV & 5 & 2nd & $\begin{array}{c}\text { Severe chlorotic } \\
\text { mottle and ringspot }\end{array}$ & 26 \\
V-TAV & 7 & 3rd to 4th & $\begin{array}{c}\text { Uneven mild chlorotic } \\
\text { mottle }\end{array}$ & 29 \\
VV1 & 5 & 2nd & $\begin{array}{c}\text { Chlorotic mottle and } \\
\text { ringspot } \\
\text { Chlorotic mottle and } \\
\text { ringspot } \\
\text { Chlorotic mottle and } \\
\text { ringspot }\end{array}$ & 24 \\
VV(1 $\left.1_{3 \mathrm{a}} \mathrm{V}_{\mathrm{CP}}\right)$ & 5 & 2nd & $\mathrm{NT}^{\mathrm{c}}$ \\
$\mathrm{VVV} *$ & 5 & 2nd & 24 \\
\hline
\end{tabular}

${ }^{a}$ Days post inoculation.

${ }^{\mathrm{b}}$ Infectivity expressed as dilution end point in $\mathrm{ng} / \mathrm{ml}$.

${ }^{c}$ Not tested. point substitutions and $1 \mathrm{nt}$ deletion in the 249-nt-long intercistronic region. In the $\mathrm{CP} \mathrm{ORF}$, there is one silent nucleotide substitution. In the $3 \mathrm{a}$ ORF, there are $5 \mathrm{nt}$ substitutions, of which two result in amino acid changes: the substitution Ile (1-TAV) to Val (V-TAV) at amino acid 88, and an in-frame ochre stop codon (UAA) in V-TAV instead of the Ser (UCA) codon present in the fourth amino acid position of 1-TAV $3 \mathrm{a}$ ORF, due to the transversion $\mathrm{C}$ to $\mathrm{A}$ at nucleotide 100 of RNA 3. The presence of this A at nucleotide 100 of V-TAV RNA 3 was not due to a cloning artifact, as it was present in 17 independently obtained cDNA clones of the $5^{\prime}$ region of V-TAV RNA 3. Furthermore, an A residue was the only nucleotide detected at position 100 when sequence determination was done with V-TAV RNA 3 as a template (not shown).

To analyze the effects of these nucleotide differences on the infectivity of transcripts $V_{3}$ and $1_{3}$, two chimeric RNA 3 clones were obtained in which a fragment including the $5^{\prime}$ UTR, the 3a ORF and most of the intergenic region (to nucleotide 1222, see Materials and Methods), and a fragment including the CP ORF and the 3' UTR were exchanged between plasmids $\mathrm{pV}_{3}$ and $\mathrm{p1}_{3}$. These chimeras yielded RNAs designated $\mathrm{V}_{3 \mathrm{a}} 1_{\mathrm{CP}}$ and $1_{3 \mathrm{a}} \mathrm{V}_{\mathrm{CP}}$. Only RNA $1_{3 \mathrm{a}} \mathrm{V}_{\mathrm{CP}}$ was infectious in tobacco leaves. A third RNA 3 was obtained by mutating the nucleotide 100 of the insert in plasmid $\mathrm{pV}_{3}$ from $\mathrm{A}$ to $\mathrm{C}$ so that a Ser codon was introduced in the place of the UAA stop. The transcript from this clone, named $V^{*}$ RNA 3 $\left(\mathrm{V}_{3}\right)_{3}$, also infected tobacco leaves. Thus, from five assayed transcripts $\left(\mathrm{V}_{3}, 1_{3}, 1_{3 \mathrm{a}} \mathrm{V}_{\mathrm{CP}}, \mathrm{V}_{3 \mathrm{a}} 1_{\mathrm{CP}}\right.$, and $\left.\mathrm{V}_{3}{ }_{3}\right)$ those with a stop at the fourth codon of the $3 \mathrm{a}$ ORF $\left(\mathrm{V}_{3}\right.$ and $\left.\mathrm{V}_{3 \mathrm{a}} 1_{\mathrm{CP}}\right)$ failed to produce infections in tobacco leaves, while those with a Ser codon $\left(1_{3}, 1_{3 \mathrm{a}} \mathrm{V}_{\mathrm{CP}}\right.$, and $\left.\mathrm{V}_{3}{ }_{3}\right)$ were infectious in tobacco leaves, suggesting that an uninterrupted $3 \mathrm{a}$ ORF was needed for infectivity. All the combinations of the in vitro transcripts that were infectious for tobacco leaves induced systemic symptoms in tobacco plants at 14 days p.i. (not shown). Virion RNAs obtained from transcript-infected plants were analyzed by direct nucleotide sequencing of the 5' $140 \mathrm{nt}$ of RNA 3 and by ribonuclease protection assay of a minus sense probe representing the 1,167 nt at the 3' end of V-TAV RNA 3. In all cases the progeny viral RNAs had the sequence of the transcripts from which they were derived (not shown).

These progeny RNAs (hereafter named TAV isolates, VV1, $\mathrm{VV}\left(1_{3 \mathrm{a}} \mathrm{V}_{\mathrm{CP}}\right)$, and $\mathrm{VVV}^{*}$ according to their RNA 3) were used as inocula to analyze the nature and time-course of symptom induction in tobacco plants. Table 1 shows that only the stock V-TAV RNA had a slow, mild phenotype and all other isolates had a fast phenotype. Thus, as shown by VVV*, a single nucleotide substitution eliminating the stop signal at the fourth codon of the p3a ORF is enough to determine a fast phenotype, and the slow phenotype of V-TAV is associated with the presence of this stop codon. Interestingly, plants infected with isolates $\mathrm{VV} 1, \mathrm{VV}\left(1_{3 \mathrm{a}} \mathrm{V}_{\mathrm{CP}}\right)$, or $\mathrm{VVV}^{*}$ had milder symptoms than plants infected with 1-TAV, although, unlike the case of plants infected with V-TAV, symptoms were evenly distributed in the leaf lamina (Table 1). Thus, the rate of spread in tobacco and symptom distribution in systemically infected leaves were determined by the 3a ORF, while the type of symptom was mostly associated with the RNAs 1 and/or 2 or RNAs 1, 2, and 3. The RNA preparations used in these experiments were similarly infectious for all isolates, as determined by dilution end point assays (Table 1). 


\section{Kinetics of virus accumulation in tobacco.}

The kinetics of accumulation of these TAV isolates were analyzed by monitoring the accumulation of $\mathrm{p} 3 \mathrm{a}, \mathrm{CP}$, or viral RNAs in the inoculated and systemically infected leaves of tobacco plants and in tobacco protoplasts. Although the timing and levels of p3a, CP, or RNA detection differed among different replicate experiments, their kinetics always showed a similar trend, as illustrated in Figure 2. In directly inoculated leaves, the p3a of V-TAV was always detected 12 to $24 \mathrm{~h}$ later than when it was from VVV*, VV1 (Fig. 2), or 1-TAV (not shown). The earliest detection of $\mathrm{p} 3 \mathrm{a}$ for the fast isolates was between 9 h p.i. (not shown) and 24 h p.i. (as in Figure 2), depending on the experiment. The maximal accumulation of p3a in inoculated leaves was at 3 to 5 days p.i. for all isolates (Fig. 2 ). At all the analyzed times, p3a accumulation was considerably less for V-TAV than for 1-TAV (not shown), VV1, or $\mathrm{VVV}^{*}$. The amount of p3a was quantified densitometrically from Western blots (immunoblots) against a range of known

1-TAV GUUUACCAACCAACAAACCACUACUGUAUAUAUAUAUCUGUGUGUGUGUGUGUGUGUGUGUGUGUGUGUUGUGUGUGUGUAAUCCUCCUAUGGCAUUUUC 100

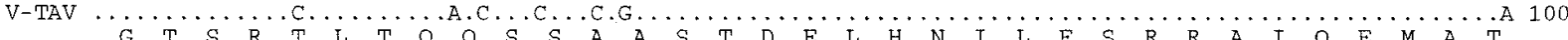
1-TAV AGGUACAAGUCGGACUCUAACACAACAGUCCUCUGCGGCAUCAACUGAUGAGCUACAUAACAUAUUAUUUAGCCGCAGAGCCAUCCAAGAGAUGGCGACA 200

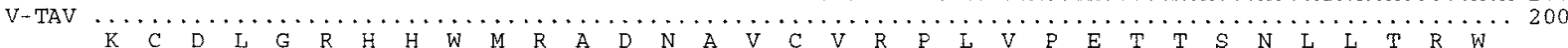
1-TAV AAAUGCGAUCUCGGUCGCCACCACUGGAUGCGCGCCGAUAAUGCGGUGUGUGUGCGACCCCUCGUUCCAGAAACCACGUCCAAUCUACUGACGCGGUGGU 300

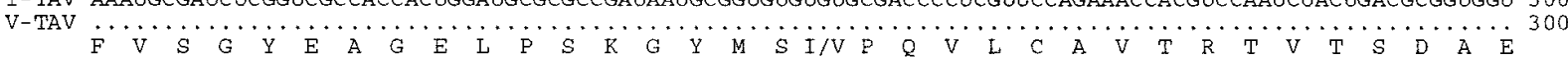
1-TAV UCGUCUCCGGGUAUGAAGCUGGAGAGUUACCAUCCAAGGGAUAUAUGAGCAUCCCUCARGUUCUUUGCGCCGUCACCAGAACAGUCACUUCAGAUGCUGA 400

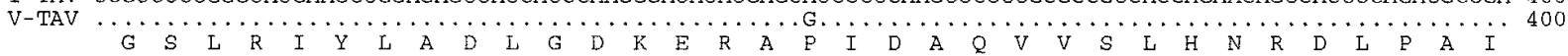
1-TAV AGGUUCCCUUCGCAUAUAUCUAGCUGAUCUCGGUGAUAAGGACGUGCACCUAUCGAUGCACAAGUCGUCAGCUUACAUAACCGCGAUCUCCCUGCCAUU 500

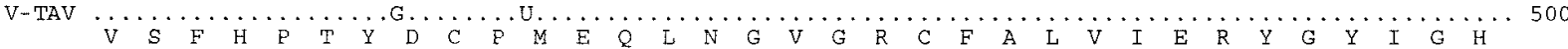
1-TAV GUCUCCUUCCAUCCUACUUAUGAUUGUCCUAUGGAACAGUUGAAUGGAGUCGGUAGGUGUUUUGCACUUGUUAUAGAAAGAUACGGUUAUAUUGGACAUA 600

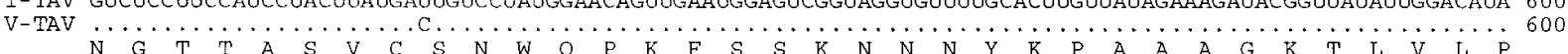
1-TAV
ACGGAACUACCGCGAGCGUGUGUAGUAACUGGCAACCGAAGUUUUCUUCGABGAAUAAUAAUUACAAGCCAGCCGCCGCAGGUAAGACUCUAGUACUACC

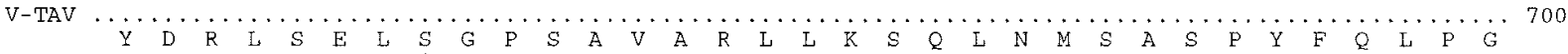
1-TAV CUAUGACAGAUUAUCUGAGCUUUCGGGACCAUCAGCCGUAGCCAGAUUACUGAAAUCGCAGCUCAAUAUGUCAGCAUCCCCGUAUUUCCAGUUACCUGGG 800

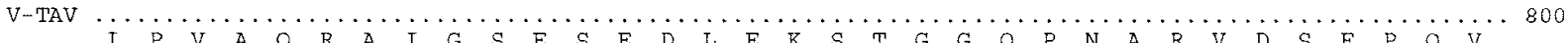
1-TAV AUACCGGUGGCUCAACGUGCGAUAGGUAGUGAGUCUGAGGAUCUUGAGAAAUCGACAGGAGGCCAACCUAACGCUAGGGUUGAUUCGGAACCGCAGGUGU 900

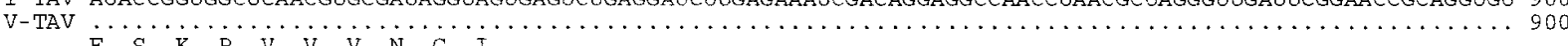
1-TAV UUUCAAAGCCGGUUGUGGUGAACGGUAUUUGAGCCUGUUGUUAUAUAUAUACGUGUAUUUGUGUUAUGUGUAUAGUAUAUAUAUGCAAGUGUAAAUCGUU 1000

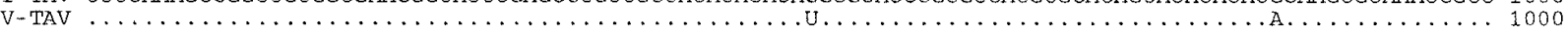
1-TAV GUGUUGUAGAUUGAUCACUUGAGUUCCAUGGAUUGGGAGGGUACACAUCUGGUUUAUCAAAGCCCGUGACAUUACUUUUUGGGUUCAAUUCCCAUUAGU 1100

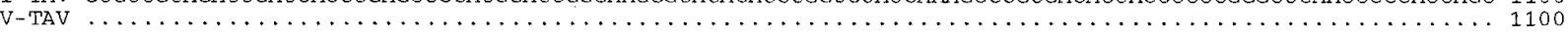
1- TAV CCCUGUCAGGUUCCUUUAUCUUCACGGAUGCUUCUCCAUGAUGUAGCGUUUAAGUAUCAAUCUGUUGUUGUUUGUGCUUAAAUUUUUCACUUAUUGUUAG 1200

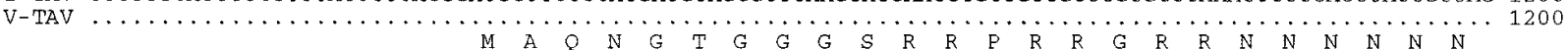
1-TAV UGUUUCACCACCGUCACACACUCUAG*AUGGCCCAAACGGUACGGGAGGAGGAAGCCGACGUCCACGUCGUGGUCGUCGUAAUAAUAACAACAACAACU 1299

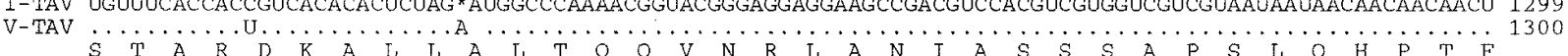
1-TAV CGACUGCUCGUGAUAAAGCUCUUUUGGCUUUGACGCAGCAAGUCAAUCGCUUAGCGAAUAUAGCUUCCUCUAGUGCGCCAUCCCUUCAACAUCCGACUUU 1399

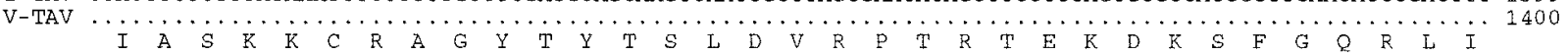
1.-TAV UAUUGCUAGCAAGAAGUGUCGUGCAGGUUAUACUUACACUUCGUUGGAUGUUCGACCGACUAGAACUGAGAAGGACAAGAGUUUCGGUCAAAGGUUAAUU 1499

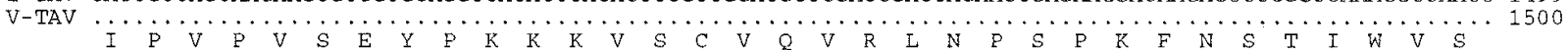
1-TAV AUCCCUGUACCCGUGUCUGAAUAUCCUAAGAAGAAGGUCUCAUGUGUGCAAGUGAGACUGAACCCAUCCCCAAAGUUCAAUUCUACGAUUUUGGGUCUCGC 1599

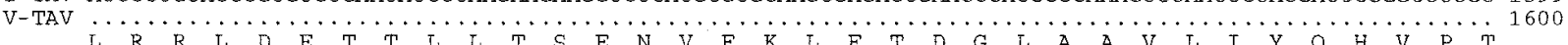
1-TAV UUCGUCGUCUGGACGAAACGACUCUUCUUACUUCUGAAAACGUGUUUAAACUGUUUCACCGACGGCCUUGCGGCCGUUCUUAUUUAUCAGCACGUUCCCAC 1699

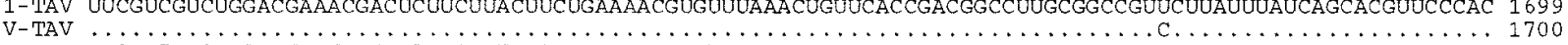

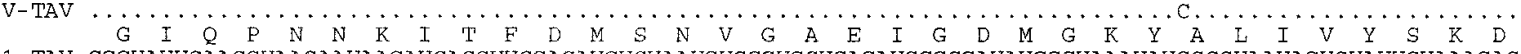
1-TAV CGGUAUUCAACCUAACAAUAAGAUCACCUUCGACAUGUCUAAUGUCGGUGCUGAGAUCGGCGAUAUGGGUAAAUAUGCCCUAAUAGUCUAUUCUAAAGAC 1799

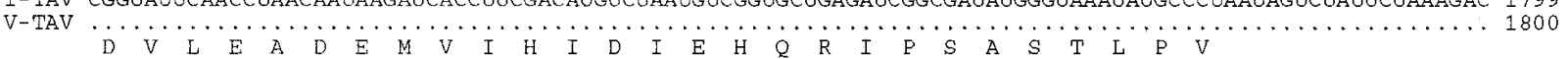
1-TAV GAUGUCCUCGAAGCCGAUGAAAUGGUGAUCCACAUUGAUAUAGAGCAUCAGCGUAUUCCUUCCGCUUCAACGCUCCCGGUGUGAUUCGACACGCAUGCAC 1899

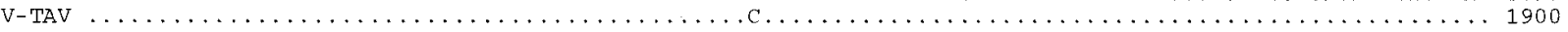

1-TAV GACGUCCGAAGACGUUAAACUACGCUUGAACUGUGUUCGAGUGUCUGAGUUGGUAGUAUUGCUCUAAACUACCUGAAGUCACUAAAUGCUUAUGCAGUGA 1999

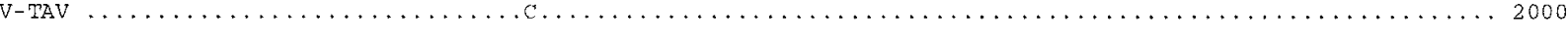

1-TAV ACGGGUUGUCCAUCCAGCUAACGGCUAAAAUGGUCAGUCAUAUCGUGAGAUAUGCCGUCGGUCUUUUUA* GUCCGAAGACGUUAAACUACGUUCGAACCG 2098

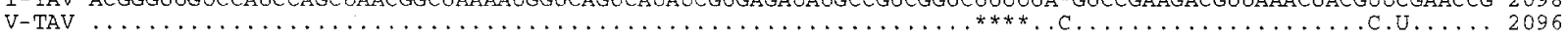
1-TAV UGUUCGAAUGUCUGAGUUGGUAGUAUUGCUCUAAACUAUCUGAAGUCACUAAACGCUUGUGCGGUGAACGGGUUGUCCAUCCAGCUAACGGCUAAAAUGG 2198

1-TAV UCAGUCAUGUCGGAAGACAUGCCGUCGGUCUUUGAUCGAUGAGGUGCCUUUGAACCCUUUAUCCCGGGGUUCUUCGGAAGGUGAGACUUGAAUUCCAUGU 22.98

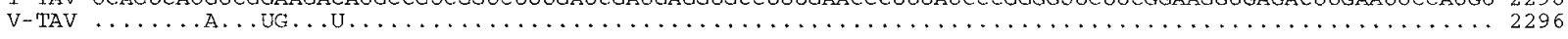

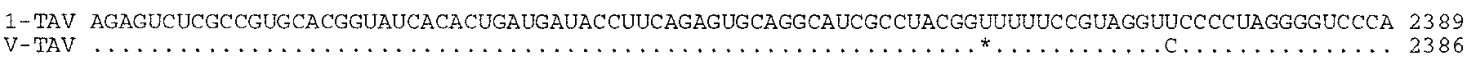

Fig. 1. Nucleotide sequence of the RNAs 3 of tomato aspermy cucumovirus (TAV) strains 1-TAV and V-TAV. For V-TAV only nucleotide substitutions related to 1-TAV are indicated. Deletions are marked as asterisks. Predicted aminoacid sequences for 1-TAV and V-TAV p3a and coat protein (CP) are also shown. Differences in the encoded sequence of V-TAV p3a related to 1-TAV are indicated: S/* at fourth position indicates the change Ser to stop and $\mathrm{I} / \mathrm{V}$ indicates the Ile to Val change at amino acid 88. 
amounts of E. coli-expressed p3a (not shown). It was found that, for V-TAV, the p3a accumulation, expressed as ng per $g$ of fresh weight leaf, was about $3 \%$ of that of $\mathrm{VVV}^{*}$ at $36 \mathrm{~h}$ p.i. (1,650 ng/g for V-TAV versus $57,750 \mathrm{ng} / \mathrm{g}$ for $\left.\mathrm{VVV}^{*}\right)$.

$\mathrm{CP}$ accumulation of V-TAV was initially less than that of $\mathrm{VVV}^{*}$, but by 2 to 4 days p.i. (Fig. 2) was at similar levels. Differences in CP accumulation between V-TAV and VVV* correlate with the observed differences in the percentage of infected mesophyll cells (Table 2). The proportion of infected mesophyll cells showed a slower rate of cell-to-cell movement for V-TAV than for $\mathrm{VVV}^{*}$ (and VV1, not shown), for which the number of infected mesophyll cells increased with time until a maximum value of about $60 \%$ was reached (Table 2). Differences in $\mathrm{p} 3 \mathrm{a}$ accumulation were much higher than differences in the percentage of infected cells (Table 2), suggesting a diminished expression of the p3a in V-TAV- versus VVV*infected cells (see below). It should also be noted that, for all isolates, the p3a accumulation pattern was remarkably different from the $\mathrm{CP}$ accumulation pattern (as in Figure 2). As infection progressed, the $\mathrm{p} 3 \mathrm{a}$ accumulation did not increase steadily, but its level dropped, at different times p.i. depending on the isolate and the experiment. We have not analyzed the significance, if any, of this maxima and minima in $\mathrm{p} 3 \mathrm{a}$ accumulation.

$\mathrm{CP}$ and $\mathrm{p} 3 \mathrm{a}$ accumulations were also analyzed in the second systemic leaf. While CP of $\mathrm{VVV}^{*}$ or VV1 was detected 3 days p.i., for V-TAV it was only detected at 5 days p.i., when the leaf was almost totally expanded and accumulation was about $1 \%$ of that for VV1 or $\mathrm{VVV}^{*}$ (not shown). In this systemic leaf the p3a was detected later (4 days p.i., when symptoms were already apparent) than the CP for VV1 and $\mathrm{VVV}^{*}$; for V-TAV, the p3a was not detected in the time span tested (not shown).

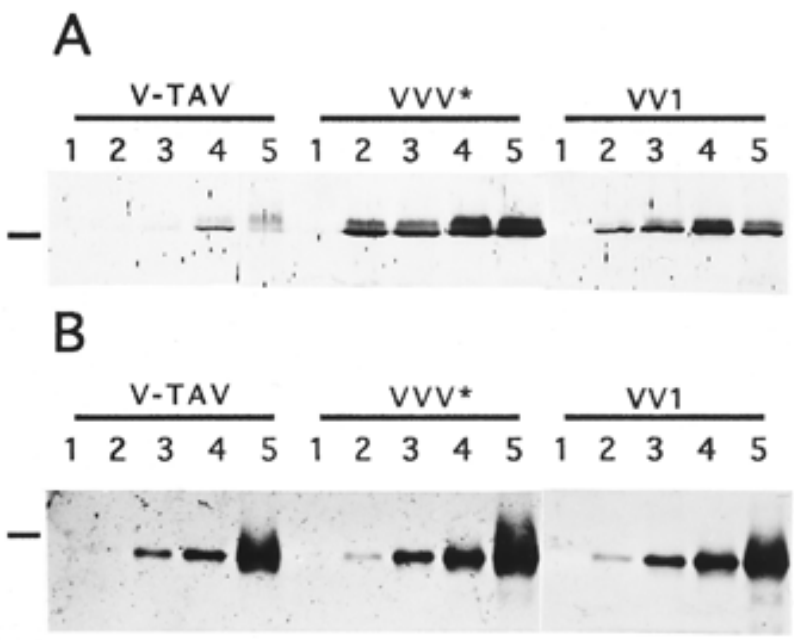

Fig. 2. Time course of p3a (A) or coat protein (CP) (B) accumulation in the inoculated leaf of tobacco plants infected with tomato aspermy cucumovirus (TAV) strains V-TAV, VVV*, or VV1. For p3a detection, protein extracts equivalent to $20 \mathrm{mg}$ of fresh tissue were electrophoresed in a $12 \%$ sodium dodecyl sulfate-polyacrylamide gel, and immunoblotted with anti-TAV p3a antiserum and alkaline phosphatase-conjugated secondary antiserum (A). The p3a antiserum detected two closely migrating proteins. The faster migrating band may be a proteolysis product of p3a. For CP detection, extracts equivalent to $4 \mathrm{mg}$ of fresh tissue were processed as in (A), with an anti-CP antiserum (B). Protein samples were taken at 0 (lane 1), 24 (lane 2), 36 (lane 3), 48 (lane 4), and 96 (lane 5) h post inoculation. Mobility of carbonic anhydrase $(34 \mathrm{kDa})$ is indicated.
The kinetics of virus and p3a accumulation were also assayed in tobacco protoplasts. As is shown in Figure 3A, in VTAV-, VV1-, or VVV*-infected protoplasts there was an early expression of p3a that was detected at $3 \mathrm{~h}$ p.i. and showed a maximum level at $12 \mathrm{~h}$ p.i. The maximum level of $\mathrm{p} 3 \mathrm{a}$ detection in V-TAV-infected protoplasts was about $20 \%$ that of VV1- or $\mathrm{VVV}^{*}$-infected protoplasts. Figure $3 \mathrm{~B}$ shows that reduction of $\mathrm{p} 3 \mathrm{a}$ accumulation was not due to lower accumulation of V-TAV RNA 3 versus V* or 1-RNA 3.

Thus, the presence of the stop codon in the $3 \mathrm{a}$ ORF of $\mathrm{V}$ TAV resulted in a reduced expression of the p3a. It should be noted that, in both protoplasts and leaves, the detected p3a band had a mobility corresponding to a full-length product of the ORF with an apparent molecular mass of $36 \mathrm{kDa}$. Thus, the presence of a full-length p3a product in V-TAV virion RNA infected cells may be due to either undetected sequence heterogeneity at nucleotide 100 of V-TAV virion RNA 3 or read-through of the fourth codon. If there is read-through it would be too inefficient to permit the $\mathrm{V}_{3}$ transcript to be infectious in intact leaves of tobacco. To test both possibilities, the in vitro translation of the p3a was analyzed from virion RNA and from transcripts.

\section{In vitro expression of the 3 a protein.}

The in vitro translation products of 1-TAV and V-TAV RNA 3 in the rabbit reticulocyte lysate translation system are compared in Figure 4. When 1-TAV or V-TAV virion RNAs or the transcripts of $1_{3}$ cDNA were used as templates, two $3 \mathrm{a}$ gene related proteins were identified by immunoprecipitation with the 1-TAV p3a antiserum (Fig. 4, lanes 1 to 2, 3 to 4 , and 7 to 8). These proteins had apparent molecular masses of $32 \mathrm{kDa}$ and $28 \mathrm{kDa}$. The $32-\mathrm{kDa}$ protein corresponds to the full-length 3a ORF product; the $28-\mathrm{kDa}$ protein corresponds in size to that predicted if initiation of translation occurred at the second AUG codon (amino acid position 35 of the 3a ORF; Fig. 1). The $32-\mathrm{kDa}$ protein was the more abundant translation product with the 1-TAV virion RNA, and the transcripts of $1_{3}$ cDNA. In contrast, with the V-TAV RNA template, both the $28-\mathrm{kDa}$ and the $32-\mathrm{kDa}$ proteins were produced at similar low levels. It is unlikely that the $32-\mathrm{kDa}$ protein in the V-TAV translation products was produced by read-through of the stop codon at the fourth position of the $\mathrm{p} 3 \mathrm{a}$ ORF, since the transcripts of the $\mathrm{V}_{3}$ cDNA directed synthesis of the $28-\mathrm{kDa}$ protein alone (Fig. 4, lanes 5 to 6). Similar results were obtained in the wheat-germ cell-free system (not shown). A more likely explanation is that the full-length p3a translated from V-TAV virion RNA is directed by an RNA 3 subpopulation lacking the stop codon that is not present in the transcript RNA.

Table 2. Progress of viral infection in tobacco leaves directly inoculated with RNA from strains V-TAV and VVV*

\begin{tabular}{lcc}
\hline & \multicolumn{2}{c}{ Percentage of infected cells $^{\mathbf{b}}$} \\
\cline { 2 - 3 } h.p.i. $^{\text {a }}$ & V-TAV & VVV $^{*}$ \\
\hline 24 & 0.3 & 0.6 \\
36 & 1.0 & 2.7 \\
48 & 4.2 & 10.0 \\
72 & 14.0 & 59.0 \\
96 & 26.0 & 57.0 \\
\hline
\end{tabular}

${ }^{a}$ Hours post inoculation.

${ }^{\mathrm{b}}$ Estimated from the number of protoplasts that fluoresce after staining with anti-TAV CP and fluorescein isothiocyanate-conjugated antisera. 


\section{DISCUSSION}

Two strains of TAV, 1-TAV and V-TAV, differ in their severity for tobacco plants: Plants infected with 1-TAV showed severe, early expressed symptoms in the first or second systemic leaves, while plants infected with V-TAV showed milder systemic symptoms in the third or fourth systemic leaves with an irregular distribution on the leaf lamina. These differences suggest a slower pattern of virus spread, and are associated with the substitution C (1-TAV) to A (V-TAV) at nucleotide 100 of the RNA 3. This introduces a UAA stop at the fourth codon of the 3a ORF in V-TAV, instead of the Ser codon present in 1-TAV or in two other reported TAV RNA 3 sequences (for strains C-TAV and P-TAV, see O'Reilly et al. 1991; Salánki et al. 1994).

Phenotypes similar to the one described here for V-TAV have been reported for CMV associated with changes in RNA 1 or in the expression of p2b (Roosinck and Palukaitis 1990; Gal-On et al. 1994; Ding et al. 1995b). Since the fast phenotype segregates with the A to $\mathrm{C}$ substitution at nucleotide 100 of RNA 3, the possible involvement of p2b or RNA 1 in the slow phenotype of V-TAV can be ruled out. A minor influence of RNAs $1+2$ in symptom determination, though, appears to exist (see Table 1).

In vitro translation experiments with transcripts from fulllength cDNA clones of 1-TAV and V-TAV RNAs 3 showed no evidence for read-through of the stop codon at the fourth po-

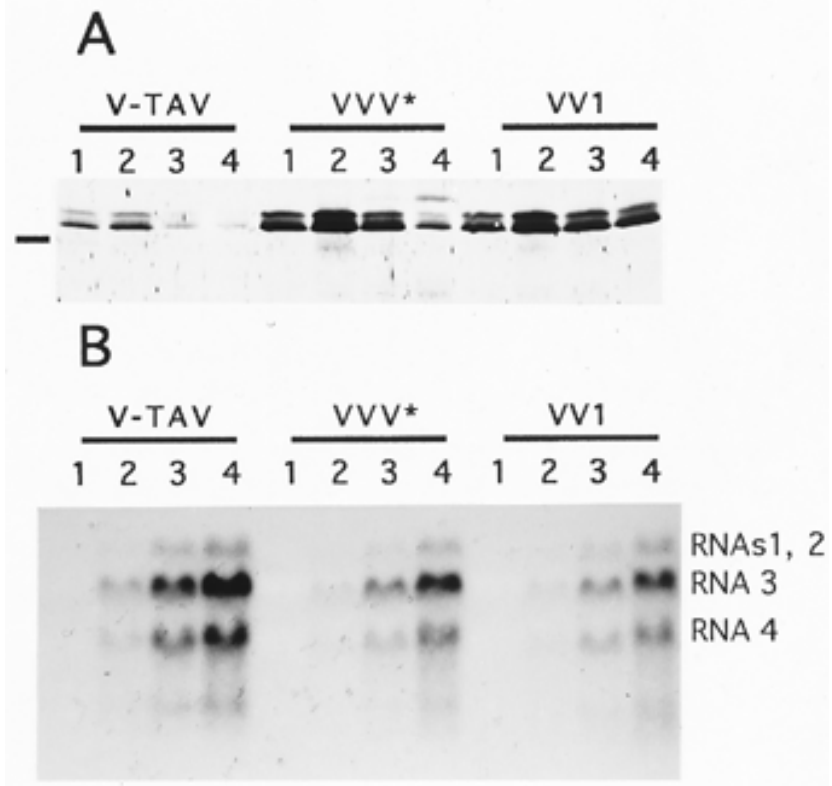

Fig. 3. Time course of p3a (A) or viral RNA (B) accumulation in tobacco protoplasts inoculated with virion RNA from tomato aspermy cucumovirus (TAV). For p3a accumulation, total protein extracts from 2 $\times 10^{5}$ protoplasts were electrophoresed in a $12 \%$ sodium dodecyl sulfate-polyacrylamide gel, and inmunoblotted with anti-TAV p3a and alkaline phosphatase-conjugated secondary antisera (A). For viral RNA accumulation, total RNA extracts from $2 \times 10^{5}$ protoplasts were electrophoresed in a $1.2 \%$ agarose, Tris-Na-acetate $\mathrm{pH} 8.0$, blotted to nitrocellulose filters, and hybridized to an RNA probe complementary to nucleotides 1,222 to 2,386 of V-TAV RNA 3 (B). Samples were taken at 3 (lane 1), 12 (lane 2), 24 (lane 3), and 36 (lane 4) h post inoculation. Electrophoretic mobilities of carbonic anhydrase (A) and TAV RNAs $1+$ 2, 3, and 4 (B) are indicated. sition of the 3a ORF. Although data from in vitro experiments cannot rule out the occurrence of read-through in vivo, the inability to direct the synthesis of a full-length p3a would explain why RNA 3 transcripts with this stop codon $\left(\mathrm{V}_{3}\right.$ and $\mathrm{V}_{3 \mathrm{a}} 1_{\mathrm{CP}}$ ) were not able to infect and spread in tobacco leaves, as opposed to RNA 3 transcripts having a Ser codon at this position $\left(1_{3}, 1_{3 \mathrm{a}} \mathrm{V}_{\mathrm{CP}}\right.$, and $\left.\mathrm{V}^{*}{ }_{3}\right)$. For $\mathrm{CMV}$ it has been shown that a p3a lacking the N-terminal 34 amino acids is nonfunctional (Kaplan et al. 1995). The data presented here suggest that the expression of a full-length p3a from virion RNA of V-TAV is due to microheterogeneity at nucleotide 100 of its RNA 3: A small fraction (as the stop codon was present in 17 independently obtained cDNA clones, as well as in directly sequenced V-TAV RNA 3) of the molecules would not have a stop at the fourth codon of the 3 a ORF and, thus, could direct the synthesis of a full-length, functional p3a.

The stop codon present at the $3 \mathrm{a}$ ORF in at least a major fraction of V-TAV RNA 3 molecules does not affect V-TAV replication in tobacco protoplasts or V-TAV infectivity in tobacco plants, compared with 1-TAV or isolates VV1, VVV*, or $\mathrm{VV}\left(1_{3 \mathrm{a}} \mathrm{V}_{\mathrm{CP}}\right)$. This stop codon does not affect the kinetics of p3a accumulation in either tobacco protoplasts or leaves, but does result in diminished accumulation. For CMV it has been extensively documented that the $\mathrm{p} 3 \mathrm{a}$ is not needed for virus replication, but that the $\mathrm{p} 3 \mathrm{a}$ is the viral movement protein (Suzuki et al. 1991; Boccard and Baulcombe 1993; Kaplan et al. 1995) with properties (Vaquero et al. 1994; Ding et al. 1995a; Li and Palukaitis 1996) similar to those of TMV 30KMP. A similar role for the homologous TAV p3a can be as-

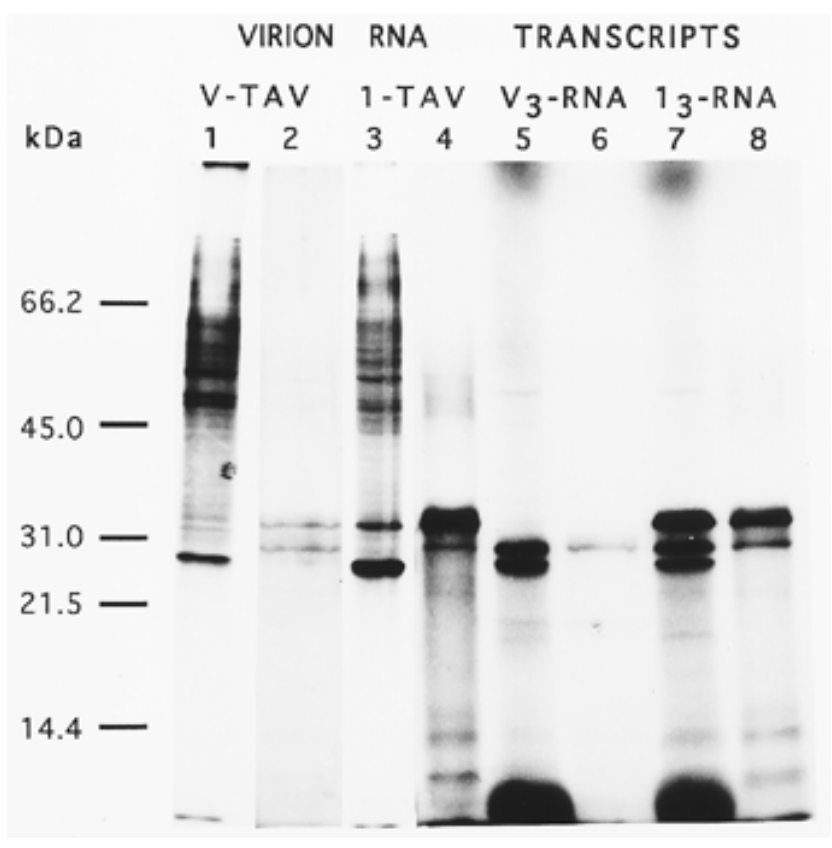

Fig. 4. In vitro translation products, in the rabbit reticulocyte lysate cell free system of tomato aspermy cucumovirus (TAV) strains V-TAV (lanes 1 and 2), 1-TAV (lanes 3 and 4), virion RNAs, and RNA transcripts $V_{3}$ (lanes 5 and 6 ) or $1_{3}$ (lanes 7 and 8). Autoradiographs show total products of in vitro translation reactions (lanes $1,3,5$ and $7,10^{5}$ incorporated cpm per lane) or products inmunoprecipitated with the anti-TAV $3 \mathrm{a}$ antiserum (lanes 2, 4, 6, and 8, 10 $\mathrm{cpm}$ per lane). No products were detected in translation reactions immunoprecipitated with preimmune antiserum (not shown). 
sumed. For V-TAV, the lesser synthesis and accumulation of p3a, compared with the other TAV isolates in this work, is associated with, and may be the cause of, the slower rate of cellto-cell spread in the leaf parenchyma from a similar number of initial infection foci, as all RNA inocula used were similarly infectious. This would lead to a delayed access to the phloem of the minor veins and, thus, to the vascular system through which infection proceeds from leaf to leaf. The timing of viral entry into the phloem will determine the success of systemic spread to young developing leaves, related to the timing of the sink-to-source transition (Leisner et al. 1992; DeJong and Ahlquist 1995). This occurs when the leaf reaches about onethird of its final size (Leisner et al. 1992), which corresponds to the delay of systemic spread observed between V-TAV and the "fast" TAV isolates (approximately 3 days), which for tobacco in the specified growth chamber conditions is the time of one plastochron. Once the virus is in the upper expanding leaves, lower rate of cell-to-cell movement would explain the uneven distribution of symptoms in the leaf lamina that occurs only for V-TAV.

The association of milder phenotypes to diminished accumulations of MP has been reported for TMV (Watanabe et al. 1987; Arce-Johnson et al. 1995). In tobacco plants transgenic for TMV MP, a MP accumulation level $4 \%$ of that in nontransgenic plants infected with wt TMV was enough to fully complement the cell-to-cell movement of a TMV mutant with a deleted MP-ORF (Arce-Johnson et al. 1995). However, in nontransgenic plants, TMV mutants showing a 50\% reduction of MP expression levels did not move cell-to-cell as efficiently as the wild type did, which resulted in reduced viral accumulation and symptom attenuation (Watanabe et al. 1987). For CMV, Kaplan et al. (1995) have reported that accumulation of CMV-MP in transgenic tobaccos is less than in nontransgenic tobacco infected with wt CMV (5 to $10 \%$ according to our estimation from their Figure 1B), but fully complemented movement of movement-deficient CMV mutants. Our results show that the diminished (approximately $3 \%) \mathrm{MP}$ accumulation in leaves inoculated with V-TAV, compared with $\mathrm{VVV}^{*}$ or $\mathrm{VV} 1$, results in less efficient virus movement, and in less virus accumulation as monitored by $\mathrm{CP}$ levels. The lower MP levels needed in transgenic plants to fully complement CMV or TMV cell-to-cell movement, relative to the higher levels needed for TAV- or TMV-infected nontransgenic plants, can be explained by the MPs being already present in the parenchyma cells of transgenic plants when CMV or TMV infection reaches them, which is not the case for the nontransgenic ones. Also, as suggested by Kaplan et al. (1995), an alteration in the time course of p3a expression may result in an impaired balance between the different viral-encoded functions. Our results, showing major variations in p3a levels at different times p.i. for V-TAV and VVV*, compared with the steady accumulation of their CPs, may support this hypothesis.

The joint quantitations of the $\mathrm{p} 3 \mathrm{a} / \mathrm{CP}$ accumulation and of the percentage of infected cells at early stages of infection contribute to understanding the role of the p3a in cell-to-cell movement. Considering that from $1 \mathrm{~g}$ of fresh tobacco leaf about 3.5 million protoplasts were obtained (data not shown), an amount of 930 million molecules of p3a per infected cell (as for V-TAV at $36 \mathrm{~h}$ p.i.) is enough for cell-to-cell movement to occur, but an amount of about 12,050 million molecules (as for $\mathrm{VVV}^{*}$ at $36 \mathrm{~h}$ p.i.) may be needed for a maximun rate of movement. Rough as they are, these data provide a first estimation of the amount of MP needed to be present in one infected cell to potentiate virus movement to the neighbor ones.

\section{MATERIALS AND METHODS}

\section{Plants and viruses.}

Strains 1-TAV and V-TAV have been described previously (Moriones et al. 1992). Virus strains and isolates were propagated and assayed in N. tabacum cv. Xanthi-nc plants. Virus purifications were performed as in Habili and Francki (1974) and total RNAs purification were as in Palukaitis et al. (1985).

\section{Construction of full-length clones representing the RNAs 1, 2, and 3 of V-TAV and RNA 3 of 1-TAV.}

cDNA was synthesized from unfractionated viral RNA with an Amersham cDNA Synthesis System Kit as described (Moriones et al. 1991), or by the polymerase chain reaction (Saiki et al. 1988) with Taq DNA polymerase (Promega, Madison, WI), after first-strand cDNA synthesis. Full-length cDNA clones to V-TAV RNAs 1, 2, and 3, or to 1-TAV RNA 3 named $\mathrm{pV}_{1}, \mathrm{pV}_{2}, \mathrm{pV}_{3}$, and $\mathrm{pl}_{3}$, respectively, were obtained by ligation of partial clones that represented overlapping segments covering the complete length of each. Full-length cDNAs to RNAs 1 and 2 of V-TAV were cloned in pUC18 or pBS(+), respectively, using restriction sites PstI and SacI. For cloning, the oligonucleotide 5'GGTGCAGTAATACGACTC ACTCACTATAGGGTTTGTCTAT 3', with a PstI site, a modified T7 RNA polymerase promoter, and $10 \mathrm{nt}$ identical to those at the 5' end of V-TAV RNAs 1 and 2 (underlined), and 5'GGAGCTCTGGGACCCCTAGG 3', with an SacI site and 13 nt complementary to those at the $3^{\prime}$ end of V-TAV genomic RNAs (underlined) were used. Full-length cDNAs to RNA 3 (V-TAV or 1-TAV) were cloned in pUC18, using the KpnI and SacI restriction sites. For cloning, the oligonucleotides $5^{\prime} \mathrm{GG}$ GTACCTAATACGACTCACTATAGGTTTACCAAC 3' with a KpnI site, a T7 RNA polymerase promoter, and 10 nt identical to those at the $5^{\prime}$ end of C-TAV RNA 3 (underlined) (O'Reilly et al. 1991), and the same primer, partially complementary to the $3^{\prime}$ end of RNAs 1 and 2 (above), were used.

\section{Construction of recombinant and mutant full-length clones of TAV RNA 3.}

Recombinant $\mathrm{p}_{3 \mathrm{a}} \mathrm{V}_{\mathrm{CP}}$ and $\mathrm{pV}_{3 \mathrm{a}} 1_{\mathrm{CP}}$ RNA 3 clones were obtained by exchanging the KpnI-XbaI and $X b a \mathrm{I}-S a c \mathrm{I}$ fragments of $\mathrm{p}_{3}$ and $\mathrm{pV}_{3}$ described above. Thus, $\mathrm{p}_{3 \mathrm{a}} \mathrm{V}_{\mathrm{CP}}$ represents a chimera having nucleotides 1 to 1,222 (representing the $5^{\prime}$ UTR and the 3a ORF, and $292 \mathrm{nt}$ of the intergenic region) of 1-TAV RNA 3, and nucleotides 1,223 to 2,386 of V-TAV RNA 3 ; inversely, $\mathrm{pV}_{3 \mathrm{a}} 1_{\mathrm{CP}}$ contains the $5^{\prime} 1,222 \mathrm{nt}$ of V-TAV RNA 3 plus the $3^{\prime} 1,167$ nt of 1-TAV RNA 3.

The mutant $\mathrm{pV}_{3}{ }_{3}$ clone was derived from $\mathrm{pV}_{3}$. To introduce a unique point mutation at the position 100 of the $\mathrm{pV}_{3}$ we used single-stranded DNA of the M13mp18 subclone with the inserted $K p n \mathrm{I}-\mathrm{Xba \textrm {I }}$ fragment from $\mathrm{pV}_{3}$ to perform oligonucleotide-directed mutagenesis (as in Kunkel 1985), with the oligonucleotide 5' CATTTTCEAGGTA 3' (the mutated nucleotide underlined) that substitutes the A residue at position 100 with a $\mathrm{C}$ residue. A M13mp18 subclone with the desired mutation was selected and its 189-bp KpnI-XcmI fragment (including the mutation) was used to replace the $\mathrm{pV}_{3}$ KpnI-XcmI frag- 
ment. All plasmids were multiplied in Escherichia coli DH5 $\alpha$ cells, and DNA was purified by standard procedures (Sambrook et al. 1989).

\section{Nucleotide sequence determination.}

For sequencing plasmids $\mathrm{p}_{3}$ and $\mathrm{pV}_{3}$ partial subclones of both plasmids were obtained in M13mp18/19 single-stranded DNA vectors. The $\mathrm{p}_{3}$ and $\mathrm{pV}_{3} K p n \mathrm{I}-\mathrm{X} b a \mathrm{I}$ fragments, and the $\mathrm{pl}_{3}$ and $\mathrm{pV}_{3}$ XbaI-SacI fragments, were all subcloned in M13mp18 and 19 in both orientations. From the M13mp18/19 plasmids, sets of overlapping clones containing progressive unidirectional deletions of the inserted DNA were obtained by the Exonuclease III method of the Erase-a-base system (Promega). Single-stranded DNA from these clones was sequenced by the dideoxinucleotide chain termination method (Sanger et al. 1977). Direct RNA sequencing was as in Fichot et al. (1990).

\section{Preparation of anti-TAV p3a and anti-TAV CP antisera and quantitation of p3a and CP immunoblots.}

Anti-TAV p3a polyclonal antiserum. A polyclonal antiserum was prepared against the product of 1-TAV 3a ORF cloned and expressed in E. coli. The 3 a ORF of 1 -TAV was polymerase chain reaction-amplified by oligonucleotides $5^{\prime}$ CCCTCGAGCCATGGCATTTTCAGGTAC 3' (upper primer that contains an $N c o$ I site coupled to the 3 a ORF AUG codon and the first $17 \mathrm{bp}$ of the $3 \mathrm{a}$ ORF), and 5' CTGGGATCCGA GCTCTCAAATACCGTTCACC 3' (lower primer complementary to the last $16 \mathrm{nt}$ of the $3 \mathrm{a}$ ORF and an $\mathrm{SacI}$ restriction site). The 865-bp PCR product was digested with NcoI and $\mathrm{SacI}$ and inserted in a similarly digested pET11d expression vector (Novagen, Madison, WI). The 3a ORF product was expressed upon induction in BL21(DE3) pLysS E. coli cells following Novagen protocols, and was prepared for injection into rabbits as in Rodriguez-Cerezo and Shaw (1991). Preimmune and anti-TAV p3a immune antisera were harvested and assayed by Western blotting for specific detection of $\mathrm{p} 3 \mathrm{a}$ from $E$. coli p3a expressing cells, and from 1-TAV-infected tobacco plants.

Anti-TAV CP polyclonal antiserum. For rabbit injection, the $\mathrm{CP}$ of 1-TAV was purified from 1-TAV-infected tobacco plants as in Habili and Francki (1974). Briefly, purified virion particles were denatured in Laemmli's sample buffer and loaded into a $12 \%$ sodium dodecyl sulfate (SDS)-polyacrylamide gel (Laemmli 1970). The gel was stained with Coomassie brilliant blue, and the CP band was excised and prepared for rabbit injection as in Rodriguez-Cerezo and Shaw (1991). Pre-immune and immune antisera were harvested and assayed as above.

Quantitation of $p 3 a$ and $C P$ in immunoblots. To perform p3a and $\mathrm{CP}$ quantitative immunoblots, the p3a (from E. coli p3a expressing cells) and the CP (from infected tobacco plants) were purified and quantified. The p3a was purified from $50 \mathrm{ml}$ of a bacterial culture expressing high levels of p3a. The insoluble protein extract was separated in a preparative, 3-mm-wide, 12\% SDS-polyacrylamide gel. After electrophoresis, the gel was stained with Coomassie brilliant blue and the p3a band excised and electroeluted with the ISCO (Lincoln, NE) concentrator apparatus and protocol. A 200- $\mu \mathrm{l}$ $40 \mathrm{mM}$ Tris- $\mathrm{HCl}, \mathrm{pH} 8.6$ solution was obtained with the p3a concentrated to $200 \mu \mathrm{g} / \mathrm{ml}$ as quantified by the BCA protein assay reagent (Pierce, Rockford, IL). The CP was concentrated to $1 \mathrm{mg} / \mathrm{ml}$ by the same method. Known amounts of purified p3a and CP preparations were immunoblotted together with time-course assay protein samples and were analyzed by band densitometry to estimate the amount of protein in the assayed samples.

\section{In vitro transcription from full-length clones.}

Full-length capped transcripts corresponding to RNAs 1, 2, and 3 of V-TAV $\left(\mathrm{V}_{1}, \mathrm{~V}_{2}\right.$, and $\left.\mathrm{V}_{3}\right)$, RNA 3 of 1-TAV $\left(1_{3}\right)$, chimeric RNAs $3\left(\mathrm{~V}_{3 \mathrm{a}} 1_{\mathrm{CP}}, 1_{3 \mathrm{a}} \mathrm{V}_{\mathrm{CP}}\right)$ and mutant V-TAV RNA 3 $\left(\mathrm{V}_{3}^{*}\right)$ were obtained by standard in vitro transcription reactions with T7 RNA polymerase (Promega) in the presence of m7GpppG (New England Biolabs, Beverly, MA). DNAs of plasmids $\mathrm{pV}_{1}, \mathrm{pV}_{2}, \mathrm{pV}_{3}, \mathrm{pl}_{3}, \mathrm{pV}_{3 \mathrm{a}} 1_{\mathrm{CP}}, \mathrm{pl}_{3 \mathrm{a}} \mathrm{V}_{\mathrm{CP}}$, and $\mathrm{pV}_{3}{ }_{3}$, respectively, were linearized with $\mathrm{SacI}$, blunt ended, and used as templates. All transcripts had the precise $5^{\prime}$ viral RNA end and one extra nucleotide at the $3^{\prime}$ end.

\section{Plants inoculation with full-length transcripts and analysis of viral progeny.}

Full-length transcripts were combined in equal amounts to prepare $\mathrm{VVV}, \mathrm{VV} 1, \mathrm{VV}\left(\mathrm{V}_{3 \mathrm{a}} 1_{\mathrm{CP}}\right), \mathrm{VV}\left(1_{3 \mathrm{a}} \mathrm{V}_{\mathrm{CP}}\right)$, and $\mathrm{VVV} *$ inocula in $0.1 \mathrm{M} \mathrm{Na}_{2} \mathrm{HPO}_{4}$ at a concentration of 200 to $500 \mathrm{ng} /$ $\mu \mathrm{l}$. Young tobacco plants were inoculated with $10 \mu \mathrm{l}$ of inoculum per leaf. At 14 days p.i., 200-mg samples were taken and total RNA extracts were obtained. The RNA extracts were screened for viral RNA accumulation by Northern (RNA) dot blot hybridization with an RNA probe complementary to the 3' 1,164 nt of V-TAV RNA 3 (TAV-probe) (results summarized in Table 1). Virion progeny was purified from each infected plant and analyzed by direct sequencing of the $5^{\prime} 200 \mathrm{nt}$ of RNA 3, using as primer the oligonucleotide $5^{\prime}$ TCCAGTGGT GGCGACCG 3', complementary to nucleotides 228 to 212 of 1-TAV and V-TAV RNA 3. The TAV-probe was used to analyze the $3^{\prime} 1,167$ nt region of RNA 3 by the ribonuclease protection assay as in Moriones et al. (1992), as this probe yielded different protection patterns for 1-TAV and V-TAV (not shown).

\section{Assays in tobacco plants.}

Virion purified RNAs of V-TAV, 1-TAV, VV1, VV $\left(\mathrm{V}_{3 \mathrm{a}} 1_{\mathrm{CP}}\right)$, and $\mathrm{VVV}^{*}$ were used as inocula. To estimate dilution end point for viral RNA populations, sets of 15 tobacco plants were inoculated with $10 \mu \mathrm{l}$ of RNA dilutions in $0.1 \mathrm{M}$ $\mathrm{Na}_{2} \mathrm{HPO}_{4}$ at concentrations of $10,1,0.1$, and $0.01 \mu \mathrm{g} / \mathrm{ml}$ and symptom induction was recorded. For time-course assays, 10 tobacco plants per treatment were inoculated at an RNA concentration of $200 \mu \mathrm{g} / \mathrm{ml}$, and samples were taken at various times p.i. (Fig. 2). One 6-mm-diameter leaf disk (equivalent to approximately $5 \mathrm{mg}$ of fresh weight) was collected from the inoculated and the second upper leaf of each plant at each analyzed time p.i. The 10 leaf disks from the inoculated or the second upper leaf were pooled in a sample, so that at every time p.i., 50-mg samples were taken for protein analysis and for fluorescent immunostaining analysis to obtain the percentage of infected cells. Each assay was done at least twice.

For protein analysis, samples were extracted in $100 \mu \mathrm{l}$ of ES buffer (75 mM Tris-HCl, pH 6.8, 4.5\% SDS, $9 \mathrm{M}$ urea, 7.5\% 2-mercaptoethanol) at $100^{\circ} \mathrm{C}$ for $5 \mathrm{~min}$, electrophoresed in a 
$12 \%$ SDS-polyacrylamide gel, and immunoblotted with the anti-TAV p3a or the anti-TAV CP antisera. Amounts of sample equivalent to $20 \mathrm{mg}$ of fresh weight were loaded for $\mathrm{p} 3 \mathrm{a}$ detection and to $5 \mathrm{mg}$ of fresh weight for CP detection. For immunostaining, protoplasts were prepared from 50-mg samples and processed as in Taliansky and García-Arenal, (1995) with anti-TAV CP and a fluorescein isothiocyanate-conjugated secondary antibody (Sigma Chemical, St. Louis, MO). After $6 \mathrm{~h}$ of digestion, protoplasts were incubated for $18 \mathrm{~h}$ before fixation for immunostaining.

\section{Time-course assays in tobacco protoplasts.}

Tobacco mesophyll protoplasts were prepared from mature tobacco leaves as in Taliansky and García-Arenal (1995). Protoplasts $\left(10^{6}\right.$ per treatment; V-TAV, VV1, and VVV*) were mixed with $10 \mu \mathrm{g}$ of virion RNA in a final volume of $400 \mu \mathrm{l}$ of $0.6 \mathrm{M}$ mannitol $\mathrm{pH} 7.0$ and transfected by electroporation at $120 \mathrm{~V} / 500 \mathrm{~F} / 48 \mathrm{ohm}$ in the BTX Electro Cell Manipulator 600 (BTX, San Diego, CA). Transfected protoplasts were incubated as in Taliansky and García-Arenal (1995).

Protoplasts were harvested at 3, 12, 24, and $36 \mathrm{~h}$ p.i., centrifuged at $600 \mathrm{rpm}$ (Labofuge Ae, Heraeus, Osterode, Germany), and extracted for protein (as above) or RNA analysis. For RNA analysis, samples were homogenized in $100 \mu \mathrm{l}$ of $100 \mathrm{mM}$ Tris-HCl, pH 8.3, 10 mM EDTA, 2\% SDS, vortexed, and extracted with one volume of phenol/chloroform $(2: 1)$. The aqueous phase was ethanol precipitated, resuspended in $100 \mu \mathrm{l}$ of $2 \mathrm{M} \mathrm{LiCl}$, and incubated overnight at $4^{\circ} \mathrm{C}$. Samples were then centrifuged at $10,000 \times g$, and the $2 \mathrm{M} \mathrm{LiCl} \mathrm{RNA}$ pellets were resuspended in $10 \mu \mathrm{l}$ of $\mathrm{H}_{2} \mathrm{O}$ and used for Northern blot analysis with the TAV-probe described above. The amount of sample equivalent to $2 \times 10^{5}$ protoplasts was used for $\mathrm{p} 3 \mathrm{a}$ or RNA detection.

\section{In vitro translation assays.}

In vitro translation assays were performed with the rabbit reticulocyte lysate and the wheat-germ, cell-free, nucleasetreated systems and protocols of Promega, in the presence of ${ }^{35} \mathrm{~S}$-labeled methionine. As templates, $1 \mu \mathrm{g}$ of 1 -TAV or VTAV virion RNA was used, or an amount of $1_{3}$ or $V_{3}$ fulllength uncapped transcript approximately equivalent to $1 \mu \mathrm{g}$ was used. Translation reactions were directly analyzed or immunoprecipitated with the anti-TAV p3a antiserum.

For immunoprecipitation, translation reactions in a volume of $25 \mu \mathrm{l}$ were made $2 \%$ with SDS and boiled for $2 \mathrm{~min}$, diluted 10 -fold with IP buffer (50 mM Tris- $\mathrm{HCl}, \mathrm{pH} 7.5,0.15 \mathrm{M}$ $\mathrm{NaCl}, 2 \mathrm{mM}$ EDTA, 1\% Nonidet P-40 [Sigma]), and incubated $1 \mathrm{~h}$ at $37^{\circ} \mathrm{C}$ with $1: 100$ diluted pre-immune or anti-TAV p3a antisera. Immune complexes were collected with Protein A Sepharose beads (Sigma). Total translation products $\left(10^{5}\right.$ incorporated $\mathrm{cpm})$ and immunoprecipitated products $\left(10^{4}\right.$ cpm) were analyzed in a $12 \%$ SDS-polyacrylamide gel, fluorographed with Amersham amplifier, dried, and exposed to X-ray film.

\section{ACKNOWLEDGMENTS}

This work was supported by grant AGF93-0101CICYT, Spain. I. M. Moreno was in receipt of a Formación de Personal Investigador fellowship, Ministerio de Educación y Ciencia, Spain.

\section{LITERATURE CITED}

Arce-Johnson, P., Kahn, T. W., Reimann-Philipp, U., RiveraBustamante, R., and Beachy, R. N. 1995. The amount of movement protein produced in transgenic plants influences the establishment, local movement, and systemic spread of infection by movement proteindeficient tobacco mosaic virus. Mol. Plant-Microbe Interact. 8:415423.

Bernal, J. J., Moriones, E., and García-Arenal, F. 1991. Evolutionary relationships in the cucumoviruses: Nucleotide sequence of tomato aspermy virus RNA 1. J. Gen. Virol. 72:2191-2195.

Boccard, F., and Baulcombe, D. 1993. Mutational analysis of Cis-acting sequences and gene function in RNA 3 of cucumber mosaic virus. Virology 193:563-578.

Chen, B., and Francki, R. I. B. 1990. Cucumovirus transmission by the aphid Myzus persicae is determined solely by the viral coat protein. J. Gen. Virol. 7:939-944.

Dawson, W. O. 1992. Tobamovirus-plant interactions. Virology 186: 359-367.

DeJong, W., and Ahlquist, P. 1995. Host-specific alterations in viral RNA accumulation and infection spread in a brome mosaic virus with an expanded host range. J. Virol. 69:1485-1492.

Ding, B., Li, Q., Nguyen, L., Palukaitis, P., and Lucas, W. 1995a. Cucumber mosaic virus 3 a protein potentiates cell-to-cell trafficking of CMV RNA in tobacco plants. Virology 207:345-353.

Ding, S. W., Li, W. X., and Symons, R. H. 1995b. A novel naturally occurring hybrid gene encoded by a plant RNA virus facilitates long distance virus movement. EMBO J. 14:5762-5772.

Fichot, M. A., and Girard, M. 1990. An improved method for sequencing of RNA templates. Nucleic Acids Res. 18:6162.

Gal-On, A., Kaplan, I. B., Roossinck, M. J., and Palukaitis, P. 1994. The kinetics of infection of zucchini-squash by cucumber mosaic virus indicate a function for RNA1 in virus movement. Virology 205:262268.

Habili, N., and Francki, R. I. B. 1974. Comparative studies on tomato aspermy and cucumber mosaic viruses. 1. Physical and chemical properties. Virology 57:392-401.

Hayes, R. J., and Buck, K. W. 1990. Complete replication of an eukaryotic virus RNA in vitro by a purified RNA-dependent RNA-polymerase. Cell 63:363-368.

Holt, C. A., Hodgson, R. A. J., Coker, F. A., Beachy, R. N., and Nelson, R. S. 1990. Characterization of the masked strain of tobacco mosaic virus: Identification of the region responsible for symptom attenuation by analysis of an infectious cDNA clone. Mol. Plant-Microbe Interact. 3:417-423.

Kaplan, I. B., Shintaku, M. H., Li, Q., Zhang, L., Marsh, L. E., and Palukaitis, P. 1995. Complementation of virus movement in transgenic tobacco expressing the cucumber mosaic virus 3 a gene. Virology 209:188-199.

Kunkel, T. A. 1985. Rapid and efficient site-specific mutagenesis without phenotypic selection. Proc. Natl. Acad. Sci. USA 82:488.

Laemmli, U. K. 1970. Cleavage of structural proteins during the assembly of the head of bacteriophage T4. Nature 227:680-685.

Leisner, S. M., Turgeon, R., and Howell, S. H. 1992. Long distance movement of cauliflower mosaic virus in infected turnip plants. MolPlant-Microbe Interact. 5:41-47.

Li, Q., and Palukaitis, P. 1996. Comparison of the nucleic acid and NTP binding properties of the movement proteins of cucumber mosaic cucumovirus and tobacco mosaic tobamovirus. Virology 216:71-79.

Moriones, E., Diaz, I., Rodriguez-Cerezo, E., Fraile, A., and GarcíaArenal, F. 1992. Differential interactions among strains of tomato aspermy virus and virus satellite RNA of cucumber mosaic virus. Virology 186:475-480.

Moriones, E., Roossinck, M. J., and García-Arenal, F. 1991. Nucleotide sequence of tomato aspermy virus RNA 2. J. Gen. Virol. 72:779-783.

O'Reilly, D., Thomas, C. J. R., and Coutts, R. H. A. 1991. Tomato aspermy virus has an evolutionary relationship with other tripartite RNA plant viruses. J. Gen. Virol. 72:1-7.

Palukaitis, P., Cotts, S., and Zaitlin, M. 1985. Detection and identification of viroids and viral nucleic acids by dot-blot hybridization. Acta Hortic. 164:109-118.

Palukaitis, P., Roossinck, M. J., Dietzgen, R. G., and Francki, R. I. B. 1992. Cucumber mosaic virus. Adv. Virus Res. 4:281-348.

Perry, K. L., Zhang, L., Shintaku, M. H., and Palukaitis, P. 1994. Map- 
ping determinants in cucumber mosaic virus for transmission by Aphis gossypii. Virology 205:591-595.

Rodriguez-Cerezo, E., and Shaw, J. G. 1991. Two newly detected nonstructural proteins in potyvirus-infected cells. Virology 185:572-579.

Roossinck, M. J., and Palukaitis, P. 1990. Rapid induction and severity of symptoms in zucchini squash (Cucurbita pepo) map to RNA 1 of cucumber mosaic virus. Mol. Plant-Microbe Interact. 3:188-192.

Saiki, R. H., Gelfand, D. H., Stoffel, S., Scharf, S. J., Higuchi, R., Horn, G. T., Mullis, K. B., and Erlich, H. A. 1988. Primer-directed enzymatic amplification of DNA with a thermostable DNA polymerase. Science 239:487-491.

Salánki, K., Balázs, E., and Burgyán, J. 1994. Nucleotide sequence and infectious in vitro transcripts of RNA 3 of tomato aspermy virus pepper isolate. Virus Res. 33:281-289.

Sambrook, J., Fritsch, E. F., and Maniatis, T. A. 1989. Molecular Cloning: A Laboratory Manual. 2nd ed. Cold Spring Harbor Laboratory, Cold Spring Harbor, NY.

Sanger, F., Nicklen, S., and Coulson, A. R. 1977. DNA sequencing with chain-terminating inhibitors. Proc. Natl. Acad. Sci. USA 74:5463-
5467

Sleat, D. E., Zhang, L., and Palukaitis, P. 1994. Mapping determinants within cucumber mosaic virus and its satellite RNA for the induction of necrosis in tomato plants. Mol. Plant-Microbe Interact. 7:189-195.

Suzuki, M., Kuwata, S., Kataoka, J., Masuta, C., Nitta, N., and Takanami, Y. 1991. Functional analysis of deletion mutants of cucumber mosaic virus RNA 3 using an in vitro transcription system. Virology 183:106-113.

Taliansky, M. E., and García-Arenal, F. (1995). Role of cucumovirus capsid protein in long-distance movement within the infected plant. J. Virol. 69:916-922.

Vaquero, C., Turner, A. P., Demangeat, G., Sanz, A., Serra, M. T., Roberts, K., and García-Luque, I. 1994. The 3a protein from cucumber mosaic virus increases the gating capacity of plasmodesmata in transgenic tobacco plants. J. Gen. Virol. 75: 3193-3197.

Watanabe, Y., Morita, N., Nishiguchi, M., and Okada, Y. 1987. Attenuated strains of tobacco mosaic virus: Reduced synthesis of a viral protein with a cell-to cell movement function. J. Mol. Biol. 194:699704. 